\title{
MÉXICO E A CONSTITUIÇÃO DA POLÍTICA DE PATRIMÔNIO CULTURAL EM MUSEUS AO LONGO DO SÉCULO XX
}

\author{
Márcio Rogério Olivato Pozzer*
}

\begin{abstract}
RESUMO: O papel histórico, político e social que as políticas públicas de patrimônio cultural em museus ocuparam no México ao longo do século XX, sobretudo a partir da "revolução mexicana" de 1910, envolveu diversos setores sociais na criação de acervos museológicos e também do Instituto Nacional de Antropologia e História (Inah) e do Instituto Nacional de Bellas Artes (Inba), sendo responsável pelo alargamento da concepção de patrimônio cultural, que implicou na inserção de práticas culturais e comunidades que estavam excluídas do patrimônio "oficial". Tais processos transformaram a política cultural mexicana em um novo paradigma para os países latinoamericanos e inseriu o México e seus museus em um dos principais destinos turísticos do mundo.
\end{abstract}

PALAVRAS-CHAVE: Patrimônio cultural; Museus; México; Memória.

\section{Mexico and the constitution of the cultural patrimony policy in museums throughout the 20th Century}

\begin{abstract}
The historical, political and social role that the public policies of cultural heritage played in museums occupied in Mexico during the XX century, especially since the 'Mexican Revolution' of 1910, involved diverse social sectors in the creation of museological collections and also of the National Institute of Anthropology and History (Inah) and the National Institute of Fine Arts (Inba), that, in turn were responsible for the extension of the concept of cultural heritage, which implied the insertion of cultural practices and communities that were excluded from the 'official' patrimony. These processes have transformed Mexican cultural policy into a new paradigm for Latin American countries and have inserted Mexico and its museums into one of the world's top tourist destinations.
\end{abstract}

KEYWORDS: Cultural heritage; Museums; Mexico; Memory.

\section{México y la constitución de la política de patrimonio cultural en museos al largo del Siglo XX}

RESUMEN: El rol histórico, político y social de las políticas públicas sobre patrimonio cultural en torno a museos en México a lo largo del siglo XX, sobre todo a partir de la "revolución mexicana" de 1910, colaboró para que se involucraran a diversos sectores sociales en la creación de acervos museológicos y también del Instituto Nacional de Antropología e Historia (Inah) y del Instituto Nacional de Bellas Artes (Inba). También fue el responsable por la ampliación de la concepción de patrimonio cultural, que implicó la inserción de prácticas culturales y comunidades que estaban excluidas del patrimonio "oficial". Tales procesos transformaron la política cultural mexicana en un nuevo paradigma para los países latinoamericanos e insertó México y sus museos en uno de los principales destinos turísticos del mundo.

PALAVRAS CLAVE: Patrimonio cultural; Museos; México; Memoria

\footnotetext{
* Doutor pelo Programa de Integração da América Latina da Universidade de São Paulo - PROLAM/USP com sanduíche pela Universidade de Salamanca (Espanha). Atualmente é professor do Instituto Federal do Rio Grande do Sul (IFRS). Contato: Instituto Federal do Rio Grande do Sul, Rua Cel. Vicente, 281 - Centro Histórico, CEP: 90030-040, Porto Alegre - RS, Brasil. marcio.pozzer@ osorio.ifrs.edu.br.
} 
O papel que a cultura cumpre na sociedade é alvo permanente das reflexões acadêmicas contemporâneas, que apresentam a cultura como a invenção coletiva e temporal de práticas, valores, símbolos e ideias que marcam a ruptura do humano em face das coisas naturais, com a instituição das linguagens, do trabalho, da consciência da morte e do tempo, do desejo como diverso da necessidade, do poder como diverso da força e da violência, do pensamento como diferenciação entre o necessário e o possível, entre o contraditório e o idêntico, entre o justo e o injusto, entre o verdadeiro e o falso, entre o belo e o feio, entre o bom e o mau; é a determinação ética da existência pela liberdade e pela culpa, a determinação política da existência pelo trabalho realizado sobre as diferenças e conflitos sociais (CHAUÍ, 1992). Em outras palavras, cultura diz respeito aos objetivos, valores e imagens do mundo que se manifestam no discurso, no direito e nas práticas rotineiras de grupos que se auto monitoram, sendo uma linguagem que se constrói a fim de pautar as relações sociais (POZZER, 2011).

Sendo assim, a noção de patrimônio cultural deveria evocar as dimensões múltiplas da cultura como imagens de um passado vivo: acontecimentos e coisas que merecem ser preservados porque são coletivamente significativos em sua diversidade. Entretanto, não é isso o que, em geral, parece acontecer: quando se fala em patrimônio cultural ou histórico, pensa-se quase sempre em uma imagem congelada, dissociada da preservação de sua significação coletiva, mantendo-se, desse modo, distante de expressar as experiências sociais (PAOLI, 1992, p. 25-28).

Dentre as políticas de patrimônio cultural destaca-se o patrimônio cultural em museus. Ainda que o termo museu tenha sua origem nos antigos templos das musas, seu significado está vinculado a outros contextos e delimitações, sobretudo ao progresso da memória escrita e figurada da Renascença e ao surgimento de uma nova civilização da inscrição, sendo possível determinar o século XIX como o momento da "explosão" de um novo paradigma (LE GOFF, 1984, p. 37-39), que se consolidou durante o século XX.

$\mathrm{O}$ debate político e acadêmico que perpassou o século XX e, de alguma forma, adentrou o século XXI, questionando concepções como o colecionismo, o museu entre quatro paredes e o patrimônio oficial, identificado apenas com alguns aspectos históricos e artísticos das sociedades que pretendem representar, impactaram não apenas nos museus, mas também no conceito de patrimônio cultural e, até mesmo, no conceito de cultura. 
$\mathrm{O}$ efeito que tais assuntos produziram nas políticas culturais mexicanas merecem destaque, uma vez que o alargamento da concepção de patrimônio cultural advindo das questões políticas e sociais trazidas pela "revolução mexicana" implicaram numa radical inserção de práticas culturais e comunidades que encontravam-se excluídas do patrimônio "oficial”, ou seja, sem serem reconhecidas, até então, pelos órgãos governamentais mexicanos.

\section{O início das políticas públicas de patrimônio cultural em museus no México}

A origem das políticas culturais mexicanas está relacionada à luta pela independência da Espanha. E, sobretudo, ao período que a sucede, de definição da identidade nacional e de rompimento com a cultura colonial. Para tanto, foram criados movimentos nacionalistas que estudaram as zonas arqueológicas com o objetivo de valorizar o passado indígena e fundado, em 1825, o Museo Nacional pelo primeiro presidente do México, Guadalupe Victoria (1824 $1828)$.

A partir do século XIX até o início do século XX, o México criou suas primeiras instituições culturais, que ficaram imersas no debate ideológico entre aqueles que defendiam a independência e os que defendiam a relação com a Espanha, entre os liberais e os conservadores, entre os criollos e os indígenas, entre os católicos e os que defendiam um Estado laico. A "vitória" do projeto "liberal" e "nacionalista" frente às demais possibilidades fez a incipiente museologia mexicana seguir um determinado rumo. Deve-se, com isso, vincular a história das políticas públicas de patrimônio cultural em museus no México à reforma de caráter liberal do sistema educacional a partir de 1833.

É possível dizer que, diferente de outros países, as coleções dos museus mexicanos de arqueologia, etnologia, história e arte não se constituíram através de compra de bens de outros países, muito menos de saques a outros territórios, como foi comum na montagem dos acervos dos grandes museus europeus. No México, por um lado, os destacados acervos museológicos foram montados pelas expedições arqueológicas ao próprio território, realizadas por dezenas de décadas, e, por outro lado, pela valorização da produção artística local, ainda que privilegiando alguns perfis e movimentos em detrimento de outros.

Esses processos estão vinculado à história dos museus mexicanos, em especial aos museus do Instituto Nacional de Antropologia e História (Inah). Ainda que a fundação do Inah tenha ocorrido apenas em 1939, a grande maioria dos museus históricos e antropológicos do 
México já vinha conformando o que viria a ser seus acervos a partir das coleções que originalmente estiveram a cargo do Museo Nacional, criado a partir da junção das "antiguidades" que estavam na capital do país e outras da universidade, que haviam sido trazidas da Ilha dos Sacrifícios, próxima à cidade de Veracruz.

Desde final do século XIX, já se notava a concentração neste museu, localizado na capital da república, ainda em poucos espaços, dos bens culturais considerados mais representativos da história nacional mexicana até aquele momento. Também era possível verificar neste período, a existência, em alguns estados mexicanos, de movimentos de caráter pedagógico que encaminhavam a formação de museus regionais, dentre eles Michoacán, Oaxaca e Jalisco.

Contudo, foi a revolução mexicana de 1910, que deixou marcas profundas nas estruturas políticas e sociais do México e que conformou a fisionomia contemporânea da política de patrimônio cultural em museus mexicana. Na cultura, assim como nas demais áreas, não poderia ser diferentes e significou uma drástica ruptura com os traços do Porfirismo $^{1}$, que nutria relação estreita com a cultura europeia, em especial a francesa. Dessa maneira, colocou-se em debate a origem e o sentido para o país dos processos de criação artística, literária, musical etc.

Em 1921 foi criada a Secretaría de Educación Pública (SEP), que passou a ser um marco das políticas sociais, mas, sobretudo educacionais e, sem dúvida, um dos momentos mais importantes da política cultural mexicana, constituindo-se como a principal catalisadora dos processos culturais. De início, com a organização de cursos, abertura de escolas e bibliotecas, edição de livros e, logo em seguida, mantenedora de uma estrutura de instituições culturais responsáveis pela criação de movimentos artísticos nacionalistas, que foram responsáveis por "reinventar" conceitos da identidade como o "nacional”, o "rural", o caráter "mestiço" e o "indígena", que obtiveram grande êxito e repercussão, tanto dentro, quanto fora do país. No campo museal, a SEP definiu com maior objetividade a função social dos museus, que ficaram encarregados de apoiar o sistema educacional federal e servir como espaços culturais para promoção dos valores revolucionários.

No geral, a política cultural mexicana estruturou-se, essencialmente, na distribuição de recursos públicos, que caracterizou um dos aspectos marcantes do período pós-revolucionário, que foi a constante contratação de artistas para a execução de obras públicas. Tal artifício foi muito utilizado para se buscar o engajamento político e social das categorias com o projeto de 
poder e sociedade que vinha sendo implementado. E que gerou também uma forte concentração dos recursos e instituições na Cidade do México, capital política do país.

Assim, embora o México se diferencie positivamente em relação aos demais países latino-americanos no que se refere às políticas de produção artística e cultural ao longo do século XX, esta política tinha um caráter demasiado discricionário, sendo constantemente questionadas pela falta de critérios republicanos e democráticos.

Contudo, ainda que alvo de severas críticas, os governos pós-revolucionários, imbuídos de forjar uma identidade nacional e patriótica deram prioridade às artes e às culturas populares, "nacionalistas". Essa preocupação política, com a criação de uma narrativa histórica, autenticamente mexicana, que caracterizou, em alguma medida, todos os países da América Latina em seus períodos pós-independência e voltou a ganhar força com os movimentos vanguardistas ${ }^{2}$ no início do século XX, se destacou no México.

A fundação do Inah em 1939 e do Instituto Nacional de Bellas Artes (Inba) em 1946 deu nova institucionalidade para as políticas de museus, representando um novo momento para as políticas públicas culturais mexicanas em geral. O Inah de início foi vital para a organização de algumas carreiras profissionais, como a antropologia e a história, bem como para a coordenação e integração dos museus existentes. Já o Inba, embora tenha sido fundamental na construção de um imaginário artístico coletivo, deve ser ressaltado que, até 1964, contava com a existência de apenas um museu, localizado no Palácio de Bellas Artes, na Cidade do México, concentrando, desta forma, as coleções públicas de arte do âmbito nacional: o Museo Nacional de Artes Plásticas (MNAP).

Em dezembro de 1934, Lázaro Cárdenas assumiu a presidência da República e começou a promover profundas transformações políticas, econômicas e sociais que, em certa medida, recuperam parte do "espírito" revolucionário das políticas mexicanas. Um dos aspectos aprofundados foi, ao final de seu governo, a criação do Inah, cuja Lei orgânica definia a fundação do Museo Nacional de Historia no Castelo de Chapultepec ${ }^{3}$ e que foi inaugurado em setembro de 1944.

\section{O Instituto Nacional de Antropologia e História (Inah)}

Os museus do Inah, sobretudo os de caráter nacional, foram responsáveis por promoverem, desde sempre, uma concepção ampla de cultura, perpassando aspectos históricos e antropológicos a partir de abordagens didáticas. Com isso, ainda que tenha predominado a idéia de concentrar em um mesmo espaço coleções provenientes de diferentes 
localizações do país, pode-se afirmar que tais instituições museológicas foram pioneiras na criação da imagem de um México pluricultural, em que a realidade nacional pôde ser entendida como resultado da articulação das diferentes culturas regionais e locais.

Augusto Urteaga Castro-Pozo (1995) afirma também que os museus do Inah teriam sido as primeiras instituições a superar a concepção tradicional de conceber os museus como lócus de desfrute cultural privilegiado, ou ainda como santuários dedicados a guardar os restos de um passado a ser cultuado e sem nenhuma conexão com o presente.

Pode-se compreender os esforços governamentais dos anos 1940 por intermédio do Inah como uma primeira tentativa em se implementar uma política nacional no campo museal, que, em alguma medida, buscava solucionar problemas de ordem técnica e financeira, chegando a desenvolver, debaixo de critérios acadêmico-científicos, que vinham sendo construídos, as especialidades museísticas no âmbito técnico e também administrativo.

Ao analisar a história do Inah, Augusto Urteaga Castro-Pozo (1995) visualiza a existência de cinco etapas em que o órgão teria buscado garantir uma infraestrutura básica e algum nível de planejamento de médio e longo prazo para as instituições.

A primeira etapa teria ocorrido ao longo da década de 1950, com a criação de um departamento de museus regionais e a tentativa de se qualificar a ação dos museus fora da capital, que, aproximadamente, dez anos depois, já contava com 30 museus sobre sua coordenação.

A seguir, durante a década de 1960, com a criação do que então se chamou de Sistema de Museus Nacionais e do Museo Nacional de las Culturas e o início de um processo de modernização dos museus regionais, que dialogavam com os anseios de um movimento setorial de âmbito mundial que discutia a renovação museográfica e atualização da função e da imagem dos museus perante suas comunidades. Assim, frente à impossibilidade de se resolver todos os problemas, o recém-criado departamento de museus regionais lançou mão de um plano geral para viabilizar o sistema de museus. No horizonte estava a melhora da gestão, com ações de organização, administração, classificação, aquisição e qualificação das exposições.

Tal década, vale lembrar, foi o auge do que David Harvey (2006) veio a chamar mais tarde de empreendedorismo urbano, com a preparação e a realização de mega eventos importantes para o México, como as Olimpíadas de 1968 na Cidade do México e a Copa do Mundo de futebol de 1970. Neste momento, ainda que existisse a consciência do papel dos museus para a cultura popular e para a educação, o foco estava na pretensão de se apresentar 
de maneira "satisfatória" a história cultural mexicana para os estrangeiros, contribuindo para incrementar o turismo.

A terceira etapa durante a administração 1970 - 1976, em que se criou a Direção de Museus e de Estímulos Escolares tentando relacionar os museus com os empreendimentos dos centros de formação do próprio Inah que passaram a se desenvolver nesta mesma época. Neste momento, fixou-se uma política geral dos museus do Inah, que começaram a estabelecer princípios normativos de alcance geral para a catalogação e manejo dos bens culturais musealizados, valendo-se das experiências dos museus nacionais e, em especial, do Museu de Antropologia. Tentou-se desenvolver um caráter multidisciplinar e condições de atender as necessidades dos pequenos museus locais e de sítio arqueológico. Coube, em tese, à Direção de Museus a condução do projeto de criação de outros centros regionais. No entanto, foram implementados apenas os planos para o Museo Cuauhnáhuac na antiga residência de Hernán Cortés ${ }^{4}$ na cidade de Cuernavaca e outro na cidade de Oaxaca. Contudo, os destaques deste período podem ser apresentados como sendo os projetos experimentais de museus escolares. Havia sido planejada a realização de 400, mas, em 1976 já funcionavam 682 projetos com este escopo. Tratava-se de pequenos projetos realizados por estudantes sob orientação de seus professores e assessoria técnica da Direção de Museus do Inah, desempenhando papel fundamental na constituição de uma educação patrimonial e, portanto, "consciência coletiva" a respeito do patrimônio cultural mexicano e o papel dos museus e suas potencialidades.

Augusto Urteaga (1995) aponta o fracasso das tentativas anteriores de se dotar o campo museal de planejamento e organização, como por intermédio de um sistema, que teriam levado à criação do Consejo de Museos e um pouco mais tarde na transformação em Consejo Nacional de Museos. Esse órgão teria a função de interligar os museus, fornecendo orientações gerais que organizassem seus objetivos e fornecesse subsídios técnicos e legais para a confecção de regulamentos internos que ordenassem seus funcionamentos e definisse os programas prioritários.

Dessa maneira, com a definição de novos critérios, a Direção de Museus fícou incumbida de coordenar e apoiar as atividades do Sistema de Museus do Inah, ampliando a circulação de informação, introduzindo alguns critérios de avaliação e iniciando, ainda que tímido, um processo de desconcentração dos museus mexicanos.

Mesmo com a crise econômica e com os sérios problemas orçamentários vividos pelos governos mexicanos, entre 1983 e 1986, foram criados sete novos museus regionais: Museo 
Regional Del Estado de Hidalgo, Museo Regional de Chiapas, Museo Histórico de Sonora, Museo Histórico de Tabasco, Museo Regional de Campeche, Museo Histórico de Acapulco e Museo Regional de Guerrero. Em consonância com o processo de fortalecimento do federalismo e de descentralização que viria, um pouco mais tarde, a ser hegemônico nos discursos políticos, o Inah transferiu coleções e objetos representativos das manifestações culturais de cada região, dando novo potencial para os bens que estavam dispersos em diferentes reservas técnicas de diversos museus.

Estes museus regionais contaram com o apoio dos governos dos estados contemplados, que também disponibilizaram coleções importantes, e que foram enriquecidas, ainda, com aportes feitos pela sociedade civil e alguns empresários. Além disso, se renovaram e ampliaram alguns dos chamados museus de sítio arqueológico, como os museus de Comalcalco em Tabasco e de Cancún em Quintana Roo e se criaram novos museus em Monte Albán, Dzibilcha'tún, Uxmal e Chichén Itzá.

Ao longo deste mesmo período, foi formatado um programa de organização, renovação e modernização de museus, que conseguiu contemplar algumas das instituições das localidades de Oaxaca, Jalisco, Morelos, Yucatán, Querétano, Colima, Ciudad Juárez, Morelia, Michoacán, Villahermosa e Chiapas. Além do mais, apoiaram-se as solicitações de governos estaduais e locais por suporte metodológico e técnico que, por meio de assessorias, auxiliaram na criação de museus municipais, que redundaram na inauguração de museus em Tabasco, Guerrero, Chiapas e outros estados, cujas administrações ficaram a cargo dos governos locais.

A quarta etapa, segundo Urteaga (1995), teria sido iniciada em 1983 com a criação do Conselho Nacional de Museus e a elaboração do Programa Nacional de Museus, que, nada mais era do que pretensão de levar para o campo da difusão cultural as orientações do Programa Nacional de Desenvolvimento do Governo Federal.

Por fim, a quinta etapa apontada corresponderia à transformação da Direção de Museus em Coordenação Nacional, iniciada em 1989 e avançando até o momento em que o autor publicou sua pesquisa em 1995. Neste período, o Instituto teria passado por uma mudança estrutural generalizada, reorganizando mais uma vez a institucionalidade do patrimônio cultural em museus da área de antropologia e história, tendo se desenvolvido um amplo programa de remodelação, crescimento, modernização e sistematização da Rede de museus do Inah. 
O Inah é o responsável, até os dias atuais, pela preservação do patrimônio cultural mexicano prévio ao século XX, cabendo a ele, as iniciativas de promoção à pesquisa, conservação, difusão e promoção destes bens culturais. Estão sob a responsabilidade do Instituto, museus, escolas, sítios, zonas arqueológicas e um acervo de aproximadamente 500 mil peças, de diversas naturezas e diferentes períodos.

Dessa maneira, o Instituto Nacional de Antropología e Historia fica responsável pela gestão de uma rede de mais de cem museus, localizados em diferentes regiões do país, dos quais, 5 são nacionais, 22 são regionais, 43 são locais e mais 32 museus são de sítios arqueológicos.

\section{O Instituto Nacional de Bellas Artes (Inba)}

No campo das artes, ainda que o Inba tenha sido criado apenas em 1947 sob o governo de Miguel Alemán Valsés (1946 - 1952), pode-se apontar a sua concepção inicial atrelada a dois momentos: o primeiro que remonta ao ano de 1927, data em que a primeira proposta de se criar um museu de arte moderna apareceu publicamente através de artigo publicado na Revista Forma e assinado por Gabriel Fernández Ledesma ${ }^{5}$; e o outro no ano de 1934, quando o presidente Abelardo Rodríguez (1932 - 1934) inaugurou o Palacio de Bellas Artes com o propósito de receber o Museo de Artes Populares, o Museo de Artes Plásticas, o Museo del Libro, as Galerías de Pintura e os Salones de Escultura Antigua Mexicana y de Estampa Mexicana.

Contudo, a abertura ao público ocorreu efetivamente em 1947, sob o nome de Museo Nacional de Artes Plásticas no Palacio de Bellas Artes que, anos mais tarde, com a inauguração do Museo de Arte Moderna, em setembro de 1964, passou a se chamar Museo del Palacio de Bellas Artes.

No que diz respeito aos museus de arte, Ana Garduño (2013), afirma que o Inba foi responsável por coordenar a reflexão e, em grande medida, a produção artística, dirigindo inicialmente as ações a respeito da arte local e global através de quatro eixos fundamentais: (1) o fortalecimento da institucionalidade por meio de uma burocracia cultural; (2) a unificação do patrimônio plástico; (3) a operação de uma galeria pública, voltada para a arte nacional e; (4) o desenvolvimento de uma estratégia de campanha para promover a arte mexicana por intermédio de exposições temporais para públicos nacionais e internacionais.

A cultura em geral, mas a arte em especial, ocupou, como já apresentado anteriormente, papel fundamental na construção de uma narrativa nacionalista desenvolvida 
pelos governos pós-revolucionários. Através da arte se buscou passar a mensagem política de modernização do Estado mexicano e também de riqueza e antiguidade cultural, reivindicando que o México ocupasse lugar de destaque no rol das nações "civilizadas" ou "poderosas".

Dessa maneira, o governo mexicano, que almejava inserir o país entre os destinos turísticos mais procurados do planeta, promoveu, por intermédio do Inba, exposições internacionais de arte mexicana (como as realizadas em 1952 no Museu Nacional de Arte Moderna de Paris, denominada "Arte mexicana, do pré-colombiano a nossos dias" ou, em 1977, no que veio mais tarde a ser o Museu de Arte Rainha Sofia, a mostra "México na Espanha: imagens de sua arte").

A exposição inaugural do Museo Nacional de Artes Plásticas, em 1947, deu ênfase ao que veio a ser a política do Inba por muitos anos: a promoção de artistas que lideravam movimentos artísticos e estavam alinhados com o projeto político em vigor: José Clemente Orozco, Diego Rivera, David Alfaro Siqueiros e Rufino Tamayo.

O período entre 1958 e 1964, em que o país foi governado por Adolfo López Mateos, concomitante ao apogeu do empreendedorismo urbano vivenciado pelo México, sobretudo na sua capital, é conhecido na bibliografia museológica mexicana como "sexênio dos museus". A partir deste período, se abandonou a concepção de galeria única para a arte produzida no México e foi dado início à montagem de uma rede de museus sob gestão do Inba. O plano inicial consistiu na abertura de quatro novos museus com perfis e vocações específicas e que pudessem ser complementares entre si. Contudo, tal projeto não contou com o apoio político que lhe permitisse lograr sucesso e os estados optaram por abrir seus próprios museus de arte.

Segundo o pesquisador Luis Gerardo Morales Moreno ${ }^{6}$, os anos 1960 foram a "era de ouro" da museologia mexicana, sendo a consagração de um projeto cultural. Segundo ele, foi neste período que se estruturou o Sistema de Museus públicos, no qual foram criados importantes museus e foi fundada a Escola de Museologia.

A arte europeia, consagrada e com muito espaço nos principais museus do mundo, só foi contar com um espaço de exposições permanentes em 1968, no, hoje denominado, Museo Nacional de San Carlos na Cidade do México. Evidentemente, este interesse tardio foi resultado da política cultural estruturada pelo período pós-revolucionário que por muito tempo privilegiou os artistas nacionais e que nos anos 1960, passou por uma reorientação de rumo, a fim de projetar o México no cenário internacional, concomitantemente aos megaeventos que aconteciam naquele período. 
Em 1974 a rede de museus do Inba foi fortalecida pela criação do Museo de Arte Contemporáneo Alvar y Carmen T. de Camilo Gil, também na Cidade do México e detentor do maior acervo de obras de Orozco em poder do Inba. Contudo, durante os primeiros dez anos o museu permaneceu praticamente vazio, uma vez que as coleções circularam por diversas cidades do mundo, principalmente da Europa, promovendo a arte mexicana.

O entusiasmo com a economia e o otimismo em torno do país ao longo dos anos 1970 refletiu-se também no campo museal. Segundo Garduño (2013), durante o governo do presidente López Portillo (1976-1982), as Instituições culturais planejaram um ambicioso processo de expansão do sistema de museus públicos, complementar à reforma da rede de instituições culturais. Contudo, a transformação da realidade econômica, com a crise fiscal do início dos anos 1980, fez com que apenas o Museo Nacional de Arte (Munal) fosse, de fato, inaugurado, obedecendo a uma "constante" da política cultural mexicana de que cada presidente aspirava construir seu próprio museu. Segundo ela, além dos problemas políticoeconômicos, um grave terremoto em setembro de 1985 também afetou a vida cotidiana do setor museal e acabou por dificultar as ações do campo.

O Inba adentra o século XXI ainda como o órgão responsável pela educação, difusão, promoção artística e pela preservação do patrimônio cultural do século XX em diante. Para tanto, o Instituto tem registrado inúmeros imóveis com valor histórico e mais outros tantos com valor artístico. Inicialmente, sob sua responsabilidade estavam também diversas Casas de Cultura, mas que foram descentralizadas e entregues para a gestão dos governos estaduais. Atualmente, conta com alguns teatros e galerias e 20 museus.

Luciana Jiménez (2008) aponta que, até final dos anos 1980, o Inba era o principal ator da produção e geração de projetos artísticos, através de suas coordenações de dança, música, teatro, artes plásticas e ópera. Até aquele período, era responsável pela Orquestra Sinfónica Nacional, Coro da Cámara de Bellas Artes, Compañías Nacionales de Ópera, Danza y Teatro, além de subsidiar a existência de outros diversos grupos, a maioria deles localizados na Cidade do México.

\section{Uma breve análise crítica da política de museus mexicana}

Pode-se verificar que a estrutura museal mexicana iniciada no final do século XVIII foi responsável por preservar e montar um grande acervo até a primeira metade do século XX, quando o Inah e o Inba, criados debaixo do guarda-chuva da Secretaría de Educación Pública, beneficiaram-se da estrutura existente para fundar novos museus. 
Vale fazer menção ao discurso do primeiro diretor do Inba, quando da sua posse em 1947, em que ele faz duras críticas ao descaso governamental com as artes mexicanas em geral:

Desde muchos años atrás hemos mirado con tristeza y con honda preocupación la deficiente atención prestada por el Estado al desarrollo del arte en México: la lamentable situación de las Galerías de San Carlos; el bochornoso embodegamiento de las colecciones nacionales de pintura del Palacio de Bellas Artes; el deterioro y la falta de conservación de la pintura mural antigua y moderna; la falta absoluta de interés hacia nuestro patrimonio pictórico en general, que se ha dispersado y se sigue dispersando, para siempre, sin que nada ni nadie lo remedie, ni de señas de siquiera querer remediarlo; la falta absoluta de apoyo a una actividad y a una producción teatrales; el increíble abandono de nuestras escuelas profesionales de artes plásticas, de música y danza; la falta total de ayuda al teatro musical - digamos ópera mexicano o de mexicanos; y así otros mil hechos lamentables. Podría pensarse que éstos son hechos lamentables sólo para los propios artistas y para las personas que abiertamente aman el arte. Podría pensarse que éste es un problema - pequeño y particular - de un grupo reducido de gente. Podría pensarse así, y de hecho así se ha quedado normado el criterio general. Pero pensar así es un error (TIBOL, 1982: p. $50)$.

A partir do ano de 1960 o México ingressou em um "momento de ouro" e, com o intuito de projetá-lo internacionalmente, foram criados diversos museus e adotadas algumas ações que ficaram conhecidas no setor museal mexicano como "reforma do sistema de museus".

No âmbito do Inba, a criação da Cidade Universitária na Cidade do México e suas obras de arte e museus provavelmente foram as ações mais relevante. Mas também a criação do Museo de Ciencias y Artes, em 1960, dentro do Parque Chapultepec, do Museo del Caracol, em 1960, do Museo de la Ciudad de México, em 1960, a reestruturação da Galeria del Palacio de Bellas Artes, que a partir de 1964 passou a ser utilizada prioritariamente para grandes exposições, realocando seu acervo para a criação da Pinacoteca Virreinal de San Diego e do Museo de Arte Moderno (MAM), ambos a partir de 1964.

Já no âmbito do Inah, ao Museo Nacional de Antropologia, em 1964, foi delegado o orçamento e a coordenação do processo de reestruturação da rede de museus de história e antropologia, para o qual se construiu o primeiro edifício monumental expressamente para servir de instituição museológica no México. A partir deste momento foi criado o Museo Nacional del Virreinato, em Tepotzotlán, em 1964, restaurado o Museo de Acolman, que estava em obras desde 1960 e, um pouco mais tarde e com um orçamento muito menor, em 1965, foi inaugurado o Museo Nacional de las Culturas.

Tal processo envolveu a reforma e restauração de diversos edifícios históricos, que foram convertidos em museus, além do surgimento dos primeiros projetos de edifícios criados especialmente para servir às funções de museu. Esta reforma gerou o impacto positivo de 
fomentar ações de planejamento nas instituições museais, principalmente com o objetivo de repensar suas vocações e perfis de museu dentro de uma nova perspectiva de complementaridade e funcionalidade dentro de um novo "sistema de museus mexicanos" que se criava. Mas, também, acabou por profissionalizar, em certa medida, diretores, curadores e demais funcionários das instituições que tiveram maiores e melhores condições técnicas, mas também maiores exigências.

As instituições culturais cresceram de maneira significativa durante os anos 1940 e 1970, organizando-se de forma bastante centralizada por decisões presidenciais. Foram criadas organizações para as bibliotecas, para a edição de livros, para o fomento à leitura, para o patrimônio cultural, para a difusão e educação artística, entre outras.

Vale observar, contudo, que a morfologia contemporânea da política de patrimônio cultural em museus no México ainda é o resultado dessa "reforma" realizada na primeira metade da década de 1960. Foram anos de otimismo com o forte desenvolvimento socioeconômico e que projetava uma ideologia oficial com um futuro idílico para o país, principalmente para a Cidade do México, inaugurando o processo de "empresariamento urbano", que alguns países e, consequentemente, algumas cidades da América Latina viriam a experimentar alguns anos mais tarde. Como caracterizou David Harvey (2006), a obsessão construtiva marcou este período, reforçando a prática herdada dos primeiros governos revolucionários, mas que demoraram algumas décadas para chegar ao setor dos museus stricto sensu, com exceção, talvez, do Palacio de Bellas Artes, que se estabeleceu em 1934.

É verdade que inúmeros projetos foram cogitados ao longo do tempo, sem uma política definida e sem a alocação dos recursos necessários. Neste período, diversos gestores da área do patrimônio receberam bolsas para pesquisa em museus de grande expressão, sobretudo nos Estados Unidos da América, sem grandes consequências para o dia a dia da política museal mexicana. A política de patrimônio cultural virou prioridade em um contexto de edificação de grandes prédios públicos, obras viárias, barragens, unidades habitacionais e outros megaprojetos que cobriram o México de canteiros de obras. O México estava se desenvolvendo!

Vale reforçar que a maior ênfase na política de patrimônio cultural derivou de uma maior atenção ao setor do turismo, que o governo buscava fortalecer. Assim, a qualificação, restauração e até mesmo a abertura de novos sítios arqueológicos, bem como suas musealizações passaram a ser prioridade para atrair cada vez mais turistas estrangeiros ao país. O presidente Adolfo López Mateos (1958 - 1964) emitiu uma portaria que desvinculava 
o Departamento de Turismo do controle do Ministério do Interior e o colocava sob o controle direto do gabinete do presidente da república.

Nessa perspectiva, se almejava transformar a Cidade do México em uma cidade com grande capital simbólico, com o que David Harvey (2006) chamou de marcos de distinção. Buscava-se que a cidade fosse reconhecida internacionalmente como a capital cultural da América Latina, fortalecendo também seu papel de liderança regional entre as nações americanas.

Dessa forma, a administração de López Mateos, que herdou o projeto de construção do Museo Nacional de Antropologia, expandiu suas limitadas pretensões iniciais e acabou por deixar o país, e, principalmente, a capital, com uma feição mais "monumental”, característica vislumbrada por sua pequena elite burguesa e que ajudou a assegurar por mais um período a governabilidade do Partido Revolucionario Institucional (PRI).

Contudo, é importante frisar que, desde o surgimento das organizações de patrimônio, houve uma disparidade entre os dois entes mexicanos, o Inah e o Inba. Tanto no que se refere ao orçamento, quanto ao peso institucional. A "reforma" da primeira metade da década de 1960 reforçou a ampliação do interesse oficial em um segmento específico do campo museal, e intensificou as escavações arqueológicas, aprofundando as desigualdades entre as duas instituições. Ou seja, consolidando o Inah como instituto com grande capacidade técnica e prestígio em âmbito nacional e até internacional, contando hoje com cerca de 120 instituições museológicas. Em contraposição ao papel do Inba, com maiores dificuldades e apenas 20 instituições museológicas. Ainda que tenha desenvolvido uma rede de museus que passam de maneira satisfatória por vários períodos artísticos na Cidade do México, o Inba segue sem grande representatividade nas demais regiões do México.

Além disso, o enfraquecimento do PRI e do projeto desenvolvimentista pósrevolucionário, perceptível a partir dos anos 1970, geraram a hegemonia neoliberal que também teve reflexos na esfera cultural e, em alguma medida, na área dos museus.

As políticas culturais que, a partir do século XIX, embora escassas, foram concebidas integralmente como assuntos de Estado, tendo nas organizações estatais sua forma institucional, tiveram tal estratégia mantida pelos governos revolucionários até os anos 1960.

Conjuntamente à "reforma" museal promovida a partir do governo de López Mateos, começa-se a perceber o surgimento de museus e equipamentos culturais privados, que se caracterizam por exercer de maneira autônoma sua gestão, mas, com a peculiaridade de estarem instituídos sempre de algum grau de dependência governamental. Na maioria das 
vezes o papel estatal está na cessão em comodato de terrenos ou edifícios públicos e repasses de recursos financeiros, que ocorrem geralmente sem contrapartida por parte dos beneficiados. Além disso, tais empreendimentos, geralmente, estavam localizados nas capitais, principalmente na Cidade do México, decisão que não estava, necessariamente, atrelada aos interesses públicos, mas, aos interesses privados que, em última instância são delegados aos departamentos de marketing das empresas, que buscam maior retorno financeiro com exposição de marca. São exemplos: Frida Kahlo (1959); Anahuacalli (1964); de Monterrey (1977-2000); Franz Mayer (1986); Amparo (1991); de Arte Contemporáneo, MARCO (1991); Soumaya (1995); Jumex (2013), entre outros.

Contudo, Ana Garduño (2013) apresenta o caso do Museo Tamayo de Arte Contemporáneo (MTAC) como sendo sui géneris. Trata-se do único museu que se integrou à rede de museus do Inba após a sua criação. Inaugurado em 1981, o MTAC era administrado pela Fundación Cultural Televisa, vinculada à companhia de televisão mais importante da indústria cultural mexicana. A construção do museu foi custeada por um importante grupo econômico de Monterrey, enquanto que o governo federal cedeu o terreno, localizado no Bosque de Chapultepec e o acervo ficou a cargo do pintor Rufino Tamayo. Alvo de severas críticas, tal museu simbolizou, ainda que não tenha sido o primeiro, o marco do fim do monopólio estatal no campo museal. No entanto, no caso do MTAC, a parceria com a iniciativa privada não funcionou. Os conflitos gerados pela vocação do museu fizeram, segundo Garduño, o pintor solicitar a tutela direta das autoridades mexicanas, fazendo com que o museu passasse definitivamente para a gestão do Instituto, acabando por representar um museu com perfil, até então, inexistente na rede, com perfil contemporâneo e internacionalista.

A mudança de paradigma de modelo de Estado se deu gradativamente e a busca por um Estado de bem-estar foi tendo seu ritmo diminuído até a conquista da hegemonia do discurso de que os governos devessem renunciar ao cumprimento de algumas responsabilidades institucionais que vinham sendo contraídas desde início do século XX, mas que nunca chegaram a se consolidar no âmbito cultural, mantendo sempre iniciativas pontuais e de baixa repercussão social, com raras exceções, mas que não lograram modificar de maneira substancial o cenário das políticas públicas de cultura no México.

Assim, os anos 1980 marcaram o início da estagnação das políticas culturais, que persistiram por três décadas. Neste período, desapareceram as empresas de cinema, a distribuidora do Fondo de Cultura Ecónomica, o Fondo Nacional para Actividades Sociales, 
o Fondo Nacional para El Desarrollo de La Danza Popular Mexicana, entre outros. O orçamento para a cultura foi reduzido e as instituições culturais públicas passam a ter que "fazer mais com menos".

No campo museal, as políticas de cunho neoliberal se transformaram em "projetos especiais", como os quatorze projetos entre 1992 e 1994, que levaram à construção ou remodelação de cinco museus e a exploração ou restauração de zonas arqueológicas que teriam como objetivo principal o incremento do turismo. Em paralelo a isso, afirma a historiadora mexicana Ana Garduño (2013), a rede de museus federais do México se mantinha com recursos básicos para sua subsistência, que se confrontava com o discurso político vigente de que as políticas culturais do país teriam alcance nacional e repercussão internacional.

O sociólogo mexicano Tomás Ejea Mendoza (2008) vai além e afirma que, ao longo do século XX, os governos mexicanos perderam a oportunidade de produzir políticas culturais de Estado. Ele aponta a criação do Instituto Nacional de Bellas Artes e do Instituto Nacional de Antropología e Historia, também como exemplos disso. Ainda que, segundo ele, sejam as duas instituições culturais mais importantes do México.

Para Tomás Ejea (2008), durante os longos anos em que o PRI governou o México, o apoio que se dava aos artistas era estabelecido por cada um dos governos e funcionários a partir de uma política com objetivos e metas pouco claras. Sendo o fomento à criação, produção, circulação e consumo artístico dependente de aspectos políticos conjecturais, assim como da influência de determinados artistas ou, em muitos casos, das preferências e gostos artísticos dos funcionários de "plantão". Para ele, o que caracteriza a política cultural do período era sua subordinação às necessidades conjunturais do grupo no poder. Ou seja, não existia uma política pública de cultura, podendo-se falar de ações dispersas, sendo que ele localiza os dois Institutos nacionais nesta mesma condição.

As criações do Consejo Nacional para la Cultura y las Artes (Conaculta), em 1988, que veio substituir a Subsecretaría de Cultura em que se aglutinavam todas as instituições dedicadas à cultura, e do Fondo Nacional para las Culturas y las Artes (FONCA), em 1989, iniciaram uma nova etapa na política cultural mexicana, chamada na época pelo presidente Carlos Salinas de Gortari (1988 - 1994) de processo de "modernização" da política cultural. Embora tal estrutura administrativa ainda seja uma agência da Secretaría de Educación Pública, e, portanto, não goze de plena autonomia, a sua fundação representou uma tentativa 
de responder aos anseios por participação, supostamente, dando maior protagonismo e organicidade para as políticas do setor cultural.

Dessa maneira, o discurso oficial do governo federal passou a ser de que a política cultural abandonava o modelo discricionário e ingressava em uma etapa democrática e participativa. Abrindo um novo debate político entre aqueles que compreendiam as ações como um avanço substantivo em diversos aspectos da política cultural e aqueles que julgavam as medidas insuficientes para romper a lógica autoritária e discricionária imperante.

Tomás Ejea (2008) propõe que as medidas não podem ser caracterizadas nem de uma forma e nem de outra, ou seja, as características democráticas das ações conviviam de forma harmoniosa com o velho sistema político autoritário. Segundo ele, o que o governo chamava de "modernização da política cultural" era, na verdade, um processo de liberalização das políticas culturais, que não podem mais ser definida, simplesmente, como autoritária, contudo, também não pode ser considerada como democrática.

Tal processo de liberalização da política cultural gerou a formação de novas instituições, atreladas às empresas privadas, que têm por objetivo principal o retorno de imagem para as suas mantenedoras e não o interesse público, necessariamente. Neste bojo, foram criadas organismos importantes como o Fomento Cultural Banamex, a Fundación Cultural Bancomer, a Fundación Jumex, a Fundación Telmex, entre tantos outros.

Esse movimento político-administrativo deve ser interpretado dentro do processo de queda de legitimidade político-social que viveu o PRI após severas denúncias de fraude eleitoral $^{7}$, dentre elas a que elegeu o presidente Salinas por uma diferença pequena no pleito de 1988. De acordo com Cristián Calónico Lucio (2006), com a criação do Fonca, o governo pretendia ganhar entre os artistas e intelectuais a legitimidade que não havia ganhado nas urnas. Victor Flores Olea, o primeiro presidente do Conaculta, chegou a afirmar em entrevista mais tarde que Salinas queria dar uma cara de "esquerda" à política cultural para equilibrar tudo o que o plano econômico viria a fazer pela direita.

Entretanto, a criação desses órgãos omite o planejamento ou a possibilidade de qualquer reorganização política que possibilitassem a confecção de políticas públicas mais robustas e de Estado, tratando-se simplesmente de uma reorganização administrativa, que passava uma unidade executora de um órgão para outro, com foco na gestão hierarquizada do presidente e sem espaço institucionalizado para a participação social. Dessa maneira, o Conaculta passou a ser um Conselho sem conselheiros. 
A institucionalização da participação, que estava presente no discurso de criação do Conselho, em que se falava sobre a importância da participação social no funcionamento das estruturas criadas e da corresponsabilização da sociedade ${ }^{8}$ também foi abandonada. Processos participativos só foram implementados parcialmente em alguns programas geridos pelo Fonca, tendo o restante das políticas funcionado, ainda, sob o caráter discricionário, principalmente seus dois órgãos de patrimônio: o Instituto Nacional de Antropología e Historia e o Instituto Nacional de Bellas Artes, cujas ações se desenvolvem sem a participação de absolutamente nenhum conselho.

Rafael Tovar y de Teresa (1994), presidente do Conaculta entre 1992 e 2000 aponta que as linhas centrais da "modernização" da política cultural deveriam ser a coresponsabilização dos próprios artistas e gestores culturais na participação das ações governamentais e a descentralização como forma de estender a rede de serviços culturais e dar vazão às necessidades e aspirações de grupos e regiões de todo o país, seguindo critérios de maior racionalidade e eficiência tanto das estruturas administrativas, quanto no manejo dos escassos recursos financeiros disponíveis.

O que se observou na prática ao longo dos anos 1990, contudo, foi a ausência de um marco jurídico adequado, bem como a falta de canais de apoio que desencadearam um processo de desaparecimento de diversas entidades da sociedade civil, que desempenhavam papel importante no âmbito cultural e que, em tese, passariam a ter maior protagonismo com a criação do Conselho. Soma-se a isso, a assinatura do Nafta em 1994, que resultou na abertura econômica mexicana para os mercados e produtos canadenses e estadunidenses, sem, ao menos, ter havido negociações que vislumbrassem preservar setores importantes para a produção cultural do México, como os setores cinematográfico, editorial e artesanal.

Porém, vale ressaltar que, com a escassez de recursos e a decorrente tomada de medidas de caráter neoliberais a partir da década de 1980, houve uma maior atenção às práticas de levantamento de dados e de produção de informações e de indicadores culturais, que, até então, eram insignificantes e dificultavam, quando não inviabilizavam, qualquer prática de planejamento das políticas e ações culturais.

Preocupados em descentralizar as políticas públicas, a recém criada Coordinación Nacional de Descentralización (Coordenação Nacional de Descentralização) foi responsável em 1994 por criar o Sistema de Información para La Planeación y Evaluación de Políticas Culturales (Sistema de Informação para o Planejamento e Avaliação de Políticas Culturais), rebatizado mais tarde de Sistema de Información Cultural do Conaculta. 
Tal sistema recebeu informações sobre a infraestrutura cultural mexicana, como museus, teatros, centros culturais, escolas de arte e casas de cultura; sobre os programas de fomento à criação e pesquisa artística, com informações sobre os grupos que receberam incentivos; festivais; revistas culturais e demais meios de comunicação, entre outros assuntos. Contudo, o Sistema de Informações Culturais deixou de ser abastecido de dados ao longo da gestão do presidente Felipe Calderón (2006-2012), decaindo a produção de informações e indicadores, sendo as duas últimas publicações, com estatísticas pertinentes ao campo museal, datadas de 2008 e 2010.

No que tange o campo museal, o principal problema, segundo Ana Garduño (2013), segue residindo na baixa institucionalidade das políticas públicas do setor, que historicamente tem ficado a mercê da vontade política de governantes, atribuindo alto caráter discricionário às decisões, assim como nas demais áreas da cultura. A consequência direta disso são os baixos orçamentos públicos para o setor, que permitem apenas a manutenção básica dos programas, incidindo sobre as dinâmicas de funcionamento das instituições que, como uma das principais implicações, passam a conviver com a predominância de exposições temporárias, realizadas por intermédio de recursos não orçamentários diretos e que demandam menores dispêndios de recursos humanos e financeiros com trabalhos e serviços de conservação e pesquisa.

Tais condições mínimas, sob as quais os museus são mantidos, dificultam também a realização de processos fundamentais para o patrimônio cultural museal, como as ações de restauração, aquisição de equipamentos e obras de melhorias espaciais e funcionais.

Para Garduño (2013), a aclamada "reforma" museal dos anos 1960 não chegou a estabelecer uma nova política cultural e a rede de museus mexicanos seguiu crescendo de maneira aleatória sem a preocupação de se criar um sistema de museus com base nas necessidades culturais das diferentes regiões do território nacional mexicano e, sobretudo, sem sanar as carências das organizações do setor, sendo as mudanças necessárias, quando muito, feitas de maneira informal, operativas e imediatas, como reações pontuais a conjecturas.

Deve-se notar, que a forma como, historicamente, a rede de museus se expandiu no México é um fator prejudicial ao processo de planejamento estratégico. A criação de novas instituições museológicas está condicionada, sobretudo, à vontade política do governante de plantão. E não às necessidades diagnosticadas no sistema, objetivando sanar lacunas observadas na rede. Este processo arbitrário caracterizou todo o século XX. 


\section{Considerações finais}

Ainda que o Estado e as políticas públicas no México padeçam dos mesmos males dos demais Estados latinoamericanos, com fortes traços de patrimonialismo, clientelismo e corrupção, é preciso ressaltar o papel político, econômico e social diferenciado que as políticas públicas de cultura, de algumas instituições museológicas e que o patrimônio cultural em geral têm ocupado, historicamente, dentro do México.

Questões que seguem sem respostas satisfatórias por todos os cantos da América Latina, como a miríade de culturas e, portanto, bens culturais que seguiam e seguem à espera de musealização, a importância da participação comunitária em todas as instâncias museológicas, assim como o papel das novas tecnologias e dos novos métodos de trabalho receberam tal intervenção que alçou o México a um papel de destaque dentro de organismos como o Conselho Internacional de Museus (International Council of Museums) e da Organização das Nações Unidas para a Educação, a Ciência e a Cultura (Icom / Unesco).

Um primeiro aspecto que merece destaque é a valorização do passado pré-colombiano mexicano e da identidade indígena na cultura moderna e também contemporânea. Esta opção política, aprofundada e transformada em política de Estado pelo período pós-revolucionário foi decisiva para a constituição da identidade nacional e do amálgama que compõem as relações sociais mexicanas até a contemporaneidade. Tais práticas foram fundamentais na composição dos ricos acervos artísticos, que, como foi apresentado, foram fruto de políticas que, por um lado, beneficiaram por anos, através de financiamentos, um perfil específico de artistas, e, por outro, de valorização de um passado pré-colombiano que redundaram em investimentos em escavações arqueológicas que acabaram por compor os principais museus mexicanos, assegurando a eles papel de destaque, inclusive internacional.

É verdade que as características culturais das comunidades pré-colombianas que viveram no que hoje é o México deixaram uma quantidade de vestígios materiais que favoreceram os processos de musealização vividos ao longo do século $\mathrm{XX}$, diferente das culturas pré-colombianas que habitaram o Brasil atual e que passaram a ter maior protagonismo no campo museal apenas recentemente com a consolidação de uma visão de patrimônio cultural que reconheceu a importância dos bens imateriais. Contudo, ainda que importante, tal característica não é, necessariamente, determinante na narrativa constituída a respeito da identidade de cada povo e de cada país. O uso dos bens materiais, assim como das tradições orais e demais perfis de "memórias" incorporam-se ao patrimônio cultural oficial conforme pretende-se contar uma história. Dessa maneira, a partir da disputa de valores, de 
versões da história, de versões da cultura, se compõe a construção do arbitrário cultural dominante.

O processo de valorização do patrimônio cultural na construção das narrativas históricas e do desenho das identidades nacionais se deu em momentos semelhantes tanto no Brasil, quanto no México. O órgão brasileiro responsável (Sphan) foi criado em 1937, enquanto que o órgão mexicano (Inah) foi criado em 1939. Entretanto, o perfil do patrimônio cultural valorizado foi distinto. No caso brasileiro, privilegiou-se o registro e tombamento de bens do período colonial, ainda que, numa das propostas de criação do órgão, feita por Mário de Andrade, havia a clara orientação para que ele se dedicasse às culturas populares brasileiras, visão esta que foi preterida. Já no caso mexicano, os registros e tombamentos, ainda que tenham ocorrido em torno dos bens coloniais também, privilegiaram-se os bens do período pré-colombiano.

No campo das artes foi diferente. O México criou uma instituição exclusiva para promover a arte popular mexicana, o Inba. Obviamente, como tentou-se demonstrar neste artigo, não se tratavam de quaisquer tipos de artes, mas de um perfil específico que estava alinhada ao projeto político em curso. Ainda assim, tal protagonismo estatal não foi verificado no Brasil e a arte e os artistas mexicanos, por muitos anos tiveram um destaque maior do que os brasileiros. Contudo, a projeção internacional dos museus de arte não se deu na mesma medida. Isso porque o México relutou em dar destaque às artes "consagradas" internacionalmente, diga-se as europeias.

Vale destacar que, decorrente do enorme esforço governamental mexicano para divulgar o país no exterior, com seus artistas populares (muralistas) e a quantidade de vestígios materiais das culturas pré-colombianas, o México despertou o interesse turístico e, portanto, deu viabilidade econômica para a exploração do patrimônio cultural mexicano. Com isso, o turismo no México passou a ser uma das principais fontes de receita, sendo que parte significativa das visitas internacionais recebidas advém do interesse pela cultura e pelos bens culturais musealizados ou não do país.

Esse interesse estrangeiro, associado à possibilidade de se expandir o ingresso de recursos financeiros fez com que a opção pela cultura popular no arbitrário cultural dominante mexicano ganhasse expressões monumentais no campo museal. Ou seja, investiu-se na constituição de grandes equipamentos museológicos, tornando-os equiparados aos principais museus do mundo. 
Nesse sentido, pode-se compreender a dimensão das contribuições de Bourdieu (1979) sobre capital cultural e arbitrário cultural dominante dentro da perspectiva dos desenhos das políticas públicas. A disputa de valores apresentada por ele vai muito além da dimensão majoritariamente explorada nesse artigo, no campo do patrimônio cultural. Ela adentra a discussão sobre a constituição de um estado social básico, que possa assegurar tempo para os indivíduos se dedicarem a questões outras que não a manutenção de sua sobrevivência, diminuindo, ou possibilitando a diminuição das desigualdades impostas pelo capitalismo. Isso vale também para o capital cultural institucionalizado, na medida em que se democratiza o acesso aos certificados, sobretudo de nível superior. Mas, também, o capital objetivado e a valorização das culturas de grupos não hegemônicos, que, o México tem conseguido avançar historicamente, sendo uma referência neste ponto.

\section{Notas}

\footnotetext{
${ }^{1}$ O Porfirismo foi um período de 30 anos durante o qual o México foi governado pelo general Porfírio Diaz, intermitentemente, desde 1876 até maio de 1911, sendo sucedido ao final pelo governo de Sebastián Lerdo de Tejada e com uma breve quebra no período entre 1880 e 1884, em que o México foi presidido por Manuel González. Porfírio Diaz contava com grande prestígio entre os militares e políticos do país, que o levou à presidência da república. Foi um período de estabilidade e progresso econômico do país, mas também graves desigualdades sociais, que concluiu com a Revolução Mexicana.

${ }^{2}$ Segundo Schwartz (1995, p. 34), no final dos anos 1920, a crescente politização da cultura latino-americana reintroduz a discussão sobre o significado e o uso da palavra "vanguarda", através da clássica oposição entre a "arte pela arte" e "arte engajada". Na realidade, a controvérsia não se dá em torno da utilização específica do termo, mas no sentido mais abrangente de uma definição do próprio estatuto da arte. Inicialmente restrito ao vocabulário militar do século XIX, acepção ainda hoje prioritária nos verbetes dos dicionários, o termo vanguarda acaba adquirindo na França um sentido figurado na área política, especialmente entre os discípulos de Saint-Simon (1760 - 1825). Para este, um dos criadores do socialismo utópico, o papel da vanguarda artística, na medida em que pretende revolucionar a sociedade, reveste-se de uma função pragmática e de uma finalidade social.

${ }^{3}$ Situado na Cidade do México, mais especificamente na colina de Chapultepec, no Bosque de Chapultepec, a uma altura aproximada de 2.300 metros acima do nível do mar, foi construído originalmente, em 1841, para ser utilizada como casa de verão do vice-rei, mas teve diversos fins ao longo dos anos, sobretudo militar. A partir de 1858 funcionou como residência oficial dos presidentes mexicanos. O edifício foi conquistado pelas tropas francesas em 1863 e, nesta fase, o palácio começou a adquirir sua configuração contemporânea, com a chegada do Imperador Maximiliano de Habsburgo, e de sua esposa, a Imperatriz Carlota, em 1864 que decidiram estabelecer ali a sua residência oficial. O Imperador contratou diversos arquitetos europeus e mexicanos para realizar vários projetos que seguiram um estilo neoclássico, em contraste com o restante do edifício de arquitetura barroca. Dessa maneira, o acervo do Museo Nacional de Arqueología, Historia y Etnografía foi dividido em duas coleções: uma parte pré-hispânica, que passou a integrar o Museo Nacional de Antropología e outra parte pós 1521, que foi destinada ao recém criado Museo Nacional de Historia.

${ }^{4}$ Hernán Cortés foi um dos principais conquistadores espanhóis. Ele liderou as ações que geraram o fim do Império Azteca e a conquista do território mexicano.

${ }^{5}$ Gabriel Fernández Ledesma (1900 - 1983): Foi um importante artista mexicano do século XX, realizando obras de diferentes linguagens; pintor, escultor, artista plástico e escritor. Fez carreira também como professor e editor, participando ativamente do Salón de La Plástica Mexicana e da Liga de Escritores y Artistas Revolucionários.

${ }^{6}$ Entrevista concedida para a pesquisa que deu origem a este artigo em 2012.
} 


\footnotetext{
${ }^{7} \mathrm{O}$ sistema de informática utilizado para registrar a contagem dos votos apresentou duas falhas técnicas, chegando a ser desligados. As suspeitas aumentaram quando o Congresso mexicano aprovou com o apoio do Partido de Ação Nacional (PAN), a destruição da documentação eleitoral que podia mostrar qual o resultado real da eleição sem que esta documentação fosse examinada.

8 Segundo Tovar y de Teresa, o presidente Salinas no dia da instalação do Conaculta, em dezembro de 1988 teria afirmado textualmente que as principais áreas de atividade do Conselho deverão se estabelecer com corpos consultivos integrados por pessoas de prestígio que, com imparcialidade e com conhecimento do meio, precisarão os critérios para atribuir recursos e promover novas ações (TOVAR Y DE TERESA, 1994, p. 363).
}

\section{Referências Bibliográficas}

ALMEIDA, Ana Maria F. A noção de capital cultural é útil para se pensar o Brasil? In: PAIXÃO, Lea Pinheiro; ZAGO, Nadir (Org.). Sociologia da educação: pesquisa e realidade. Petrópolis, RJ: Vozes, 2007.

BOURDIEU, Pierre. Les trois états du capital culturel. Actes de la recherche en sciences sociales, Paris, $\mathrm{n}^{\circ} 30$, nov. 1979, p. 3-6.

CALÓNICO, Lucio Cristián. Fortalezcamos al Fondo Nacional para la Cultura y las Artes: en Fondo Nacional para la Cultura y las Artes. 18 años de inversión en el patrimonio vivo de México. México D. F.: Conaculta, 2006.

CHAUÍ, Marilena. Política cultural, cultura política e patrimônio histórico. In: $O$ direito à memória: patrimônio histórico e cidadania. São Paulo: DPH, 1992.

EJEA MENDOZA, Tomás. La política cultural de México en los últimos años. México D.F.: Casa del Tiempo, $n^{\circ}$ 5-6, 2008, p. 2-7.

GARDUÑO, Ana. Biografía de una institución cultural: el Inba de México. Red museal y práxis coleccionística. Revista Grafia, v. 10, nº 1, 2013, p. 9-25.

HARVEY, David. A produção capitalista do espaço. 2. ed. São Paulo: Annablumme, 2006.

JIMÉNEZ, Luciana. Politicas culturales en México: una encrucijada por descifrar. In: CANELAS, Antonio Albino; BAYARDO, Rubens (Org.) Políticas Culturais na IberoAmérica. Salvador: Edufba, 2008.

LE GOFF, Jacques (Org.). Enciclopédia Einaudi: memória e história. Lisboa: Imprensa Nacional, 1984.

PAOLI, Maria Célia. Memória, história e cidadania: o direito ao passado. In: CUNHA, Maria Clementina Pereira da (Org.). Direito à memória. 2a ed. São Paulo: Departamento do Patrimônio Histórico/ SMC/ Prefeitura do Município de São Paulo, 1992, v. 1, p. 25-29.

POZZER, Márcio Rogério Olivato. Políticas públicas para o patrimônio cultural na América Latina: a experiência brasileira e equatoriana e o papel do Banco Interamericano de Desenvolvimento. 2011. Dissertação (Mestrado em Integração da América Latina) - Programa Interunidades em Integração da América Latina, Universidade de São Paulo, São Paulo, 2011. SCHWARTZ, Jorge. Vanguardas latino-americanas: polêmicas, manifestos e textos críticos. São Paulo: Edusp: Iluminuras: Fapesp, 1995.

TIBOL, Raquel. Instituciones del arte y de la cultura artística. Revista Processo, $\mathrm{n}^{\circ}$ 317, año 6, 1982.

TOVAR, Y DE TERESA, Rafael. Modernización y política cultural. México D. F.: Fondo de Cultura Económica, 1994.

URTEAGA, Augusto Castro-Pozo. Museos y Exposiciones. In: Inah: una historia. V. 1. México: Inah, 1995. 